\title{
Experience and Enlightenment of the Governance Structure of German Universities
}

\author{
MA Xiao-jun \\ College of Mechanical Engineering \\ Jiamusi University \\ Jiamusi, China \\ mjzx2009phd@163.com \\ PAN Hong-wei \\ Institute of Physical Education \\ Jiamusi University \\ Jiamusi, China \\ jdgjyjs@163.com
}

\author{
$\mathrm{LI} \mathrm{Mu}$ \\ School of Finance and Business \\ SHNU \\ Shanghai, China \\ shangshidalimu@163.com
}

\author{
LI Chun-jiang* \\ Academic Affairs \\ Jiamusi University \\ Jiamusi, China \\ jmslcj@sohu.com
}

\begin{abstract}
The paper describes the development history of German university governance structure, and analyzes the governance model characteristics of German universities: decentralization, self-management, principal responsibility and stakeholder participation, academic autonomy model. Through the research on the governance structure mode of the German university, explore the theoretical basis, historical evolution, institutional arrangement and value implication of German university governance structure, and combine them with the present governance structure situation of Chinese universities to provide experience and reference for university governance structure of our country, predicting the future trend of Chinese university governance structure.
\end{abstract}

Keywords-German university; governance structure; governance model; experience reference

\section{INTRODUCTION}

The university governance structure is an academic statement, but it has been always concerned by the society in a "hotspot" perspective. In the media (especially network media) communication level, the academic power and its representative teachers in university governance structure are usually considered as the natural weak under the existing system. Through the help of the media, the administrative authority of universities has often been "demonized"; and a variety of academic corruption frequently exposed also tend to blame the so-called academic power "administration". Whether it is biased opinion or not, the general concern of the public has made the reform of university governance structures no longer a simple internal affair of the university. Within the university, with the rapid development of the popularization and internationalization of China's higher education, the internal and external environment of our country's higher education development is undergoing tremendous changes. The construction of university governance structure which can

Reform project of Heilongjiang Province: (JG2014011046), Jiamus University teaching research project (2016JW1009), Jiamusi University degree and postgraduate education teaching reform project (JGXM-JDY2016011)and Heilongjiang institute of higher education project(16G206) (sponsors).

*Corresponding author: LI Chun-jiang,jmslcj@sohu.com adapt to the changing environment has become the basic consensus and urgent task of universities.

\section{THE DEVELOPMENT COURSE OF THE GERMAN UNIVERSITY GOVERNANCE STRUCTURE}

Modern German universities have experienced many twists and turns and rise and fall. The status of university governance has been always closely linked with national conditions. In nineteenth century, the European power was in its heyday, the country had placed high hopes on universities, nationality and nationalism prevailed. In 1810, Germany founded Humboldt University of Berlin, trying to save the country in peril. The most valuable is that "university autonomy" has been first determined as an idea of university, "the country cannot expect the university directly and fully serve the country". In the university autonomy, the German constitution stipulates that the state government only has the administrative power of diplomacy, finance, postal service and transportation, and does not enjoy the administrative power of education. The German universities implement a high degree of autonomy.

In 2005, the German federal government conducted the "excellence program" to create "elite university". Professors of German elite universities has a higher status; the Council can't include members of the external. The traditional private docent system of Germany is conducive to academic freedom and university autonomy, young private docent has more time and energy to conduct research. Secondly, the ministry of education has supervisory power on university professors and their performance. According to the law, the German universities is a national institution, the German university professor is appointed and paid by the state, all professors, whether it is formal or temporary, are state officials. The bureaucratic system interferes with university autonomy, university's freedom to appoint teachers, and teachers' freedom to flow in different universities through the change of university teacher establishment. Germany's national autonomous university system is in crisis. 
Germany implements federal system, the state is responsible for higher education and the country has a regulatory authority and responsibility for the university. According to the study of the association of the European university, the universities in the states of Germany are rated as "moderate", and the financial and staffing autonomy and academic freedom are also rated as "medium". The country has the power to appoint and dismiss president. The characteristics of German university governance are the combination of university autonomy and nationalism. Influenced by Hagel's theory of state intervention, university autonomy and national service are both respected in Germany, and the country running the university has been its tradition. One of the reasons is that the university autonomy thought is ingrained, academic freedom has been widely approved, "Humboldt tradition" is still the guiding ideology of educational policy. In 1976, Germany promulgated the "general law of higher education", the fifty-eighth rule of which stipulates: "institution of higher learning is a legal body, but also a national institution, and rules itself within the bounds of the law."

\section{THE CHARACTERISTICS OF THE GERMAN UNIVERSITY} GOVERNANCE MODEL

\section{A. Decentralization of Power}

German university governance is influenced by many historical factors. Germany, as a geographical unit, has experienced several divisions in the history, but the German education administration has always belonged to local decentralization. After the founding of the country in 1949, West Germany inherited this tradition, namely education legislation belongs to the states, and the federal constitution only provides some of the most basic principles. East Germany's constitution also gives states a certain degree of educational administration, but the most important legislation is determined by the central government, which is largely influenced by the Soviet education model. After the reunification of Germany in 1990, the German education administration still belonged to the local decentralization, and constantly find a balance between centralization and decentralization through the legislation.

The "decentralization" of German universities can be traced back to the period of religious reform. The religious reform and expansion of local power allow German universities to become local institutions with the purpose to cultivate theologians and jurists, and later founding university has become a purposive behavior of countries. In the process of competing with each other, the sovereign of countries clearly recognized the importance of the university to its rule and national interests. The Bonn basic law, promulgated in 1945, established the states enjoy "cultural sovereignty", which means that the legislative power and the administrative authority of cultural education, including higher education, belong to states.

\section{B. Self Management of University}

The self-management of German universities is truly independent after the separation from academic governance, and it begins to focus on the development direction of efficiency and effectiveness. Self-management as a governance model has been strengthened, firstly by giving managers a certain administrative decision-making power, weakening the academic autonomy and government regulation. Secondly, specify their personal basic responsibility and abstract: since the 1990s, Germany and European countries set off a wave of management change in the field of higher education. It has become the inevitable trend of the reform of higher education in the world to change from control to coordination and replace management with governance. Germany university governance has its base of educational tradition, politics, economy and culture, the experience of German university governance can provide valuable inspiration for the reform of China's university governance.

In addition, hierarchical management structure has also strengthened the concept of changing the traditional management mode. Through the leadership development and the affection to the appointment of school level and central level staff, German universities have strengthened their rights to know, to raise an objection, to develop solutions for other universities, and to make decisions. In traditional German universities with the characteristics of "Professor University", the university management is controlled by authoritative professors. However, with the passage of time, "Professor University" suffered a crisis, and was eventually replaced by the committee composed by representatives in "Community University" reform in the 1960s.

Although the committee's management authority has changed for several times afterwards, the tradition of German universities participating in self-management in many departments has been retained. The state government is still in control of higher education institutions, but changes its original control on university investment and development process to the control of the output of the university. These changes will have an impact on the traditional university autonomy, but it helps higher education institutions to start flexible organization and management policies, implement key plans, and create more research income. University autonomy has not only changed the relationship between higher education institutions and government, but also prompted the university to form an open system facing the international community.

\section{The Principal Responsibility System}

The principal responsibility system is the basic principle of German university governance. The president is elected from full professors by the general assembly of the university faculty and staff. The principal is the leader of the school, whose responsibility is legal. Taking Colleges and Universities Law af Bavaria State as an example, it stipulates the principal as the leader of school, and is mainly responsible for handling all the things in school decision-making body which does not belong to the range of other conferences on behalf of the school. Principal is the chairman of school representative assembly and the school review boards. He has the right to convene and preside at meetings of the two institutions, and has the power to veto their resolution. If encountering a defiant, the principal can dissolve related conferences, and hold new elections to restore his administrative work. For urgent business, the principal can make the necessary decisions and take necessary measures for the main institutions of the school. Principal of 
the German universities plays the soul part of the university, his position is very important.

The principal responsibility system of the German universities was established in the reform of "Community University". "Community University" is an important achievement of German university reform in 1960s-1970s. In the "Community University", all the important decisions of the university are made by four delegations in the Committee after their discussion. The decision-making model of involving all members not only consumes time and energy, but also has unclear responsibilities and powers and unclear reward and punishment. Therefore, many states have carried out the exploration of university internal organization and management mode, including: personal responsibility, that is, strengthen the power of the principal and dean through the extension of the term and expansion of their powers, including letting the dean become the superior of professors; separate the administrative and decision-making department from supervising department.

\section{Stakeholder Involvement}

In current German university governance, the government regulation has been weakened, replaced by stakeholders' supervision and guidance. In the university governance involving stakeholders, the government regulation is conducted by the science department and the state government. In the governance structure of the German universities, the university has set up board of directors. The Council only has the authority to consult, and it is the representative of the interests of the society, researchers, industry and cultural institutions. The Council was eventually replaced by an agency with more responsibility and authority. For example: the agency of Brandenburg is Brandenburg Higher Education Council, the agency in the state of Lower Saxony is University Higher Education Council, and the agency in universities with external financing mode is the University Council of funding agencies. Together, they form the participants in university governance. Different stakeholders represent the interests of their respective fields, and they have the power to safeguard the interests of their respective groups.

German university stakeholders are from two aspects, one is groups and institutions providing funds for the university, the other is groups and institutions which oversee the university. Since 1990s, Germany's economic growth has been slow, which has reduced the government's support for the financial resources of higher education. At the same time, the "new public management" movement, which is characterized by liberalization and marketization, is spreading to Germany. Under the influence of the movement, German government proposes efficiency requirements while supporting the university as always, and hopes to improve university management through management technologies such as decentralization, relaxing restrictions, and authorizing private institutions, so as to improve the running efficiency. The diversification of university investors and supervision and management make the German universities change the original image of government institutions, and become a special institution with many stakeholders.

\section{E. Academic Autonomy}

The academic autonomy of the German universities is operated by the committee of academic autonomy. On the central level, the committee of academic autonomy exercises their functions through the university review boards and original council, while on schools and colleges level, they exercise their functions through school or faculty review boards. Its essence is to exercise its functions through participation in decision-making. This way of academic autonomy is largely influenced by the proportion of voting power and seat of the committee. The proportion of voting power and seat in the committee determines the fairness of the decision, and even will affect the final result.

The decision-making power of academic autonomy committee has different ranges in the appointment of professors, funding allocation, coordination of research, appointment and removal of the president's office, internal organization and planning and other aspects. What's most critical is that this decision is to a large extent binding upon specific administrative personnel. German university academic autonomy is based on the principle of academic freedom. Germany is the birthplace of academic freedom idea and system. So far, academic freedom is still the core value that German universities spare no effort to maintain. Germany is the earliest country to bring the principle of academic freedom into the national constitution in the world. As early as in the 1849 Constitution of Frankfurt has already written academic freedom and personal freedom, freedom of speech, freedom of religion into the law together. Article V of current German Basic Law also clearly stipulates that "the university has the freedom of art and science, research and teaching". While ensuring the academic freedom of the university, the law also creates the conditions for scholars to manage the academic.

\section{THE ENLIGHTENMENTS OF GERMAN UNIVERSITY GOVERNANCE MODE}

German university governance mode is not solid. It's a variety of patterns moving, changing and developing according to the needs of reality. German university governance mode has its advancement, and the development of higher education around the world has similarity. The experiences and specific practice of Germany university governance can give us five enlightenments.

\section{A. The changing of the role of government}

German higher education administrative management implements decentralization system, giving more management power to states and universities which helps the states develop higher education according to the real conditions, improving the adaptability of education and education resource utilization efficiency. The government's control and management of university are necessary, but too much government's control is not conducive to the development of the university. In our country, the government is an "almighty government". We should change the government's position in the management of higher education and its scope and operating methods of power. That is to change from the original government centralized management into appropriate government regulation, and allow more interests relevant institutions involved in the university governance, realizing the changing from government unilateral 
governance to multilateral governance. The government should change its role from specific management practitioner to the mentor, finally realizing that the government, society and universities jointly participate in the management of higher education affairs.

\section{B. Play the leading role of the president}

President of German university plays an important role in fighting for resources and maintaining the autonomy of university. As the soul and leader of the university, university president plays an irreplaceable role in the prosperity and development of the university. In Germany, the president of the university is elected by university faculty meeting from full professors. As a school leader, the president has absolute leadership in the school, and can be re-elected and reappointed consecutively. Our country's university president is appointed by the government in most cases, who works as the role of policy executors. Because of this and term limits, it is difficult for the principal to form his own educational philosophy and style. Therefore in order to realize the principal governing school and make full use of the leading role of principal, we must have reasonable management system and personnel system, and give principals greater school management autonomy, support and encourage the principal to follow the law of higher education, thus forming unique school-running ideas and education concept with individual character.

\section{Let professors govern university}

Professors have supreme status in the German university governance. Knowledgeable, experienced professors who understand management play a leading role in Germany university governance. As the core of university governance, the principal is elected from full professors by university faculty meeting. Even after the democratic reform in university, full professor representatives are still in the majority in many institutions. The tradition of professor managing the school has no fundamental changing in the federal Germany university internal management. The professor holds an absolute advantage of the seats in the highest authority of the university school representative assembly and review boards with a wide range of functions and members of some standing committees. Let professor who understands the academic govern school, which is advantageous to the development of university as a teaching, academic and research institution. In our country, although professors has got the respect what they deserve in terms of academic, they lack more participation in university governance. Implementing "professor managing" governance philosophy through legislation should be an important aspect of the current higher education reform in China.

\section{Academic autonomy and self management}

German university's academic autonomy committees are taken seriously and has certain decision-making power and influence. But the role of academic autonomy committee in university governance in our country has not been taken seriously. To change the situation, make full use of the role of academic autonomy committee, and create good academic environment for scholars to grow, we must give academic committee the decision-making power in title assessment, degree awarding, education teaching development planning, discipline research and planning and other academic fields, improving academic committee's status and power in decision making. At the same time, let the academic committee become the principal's consultative and balance machinery of teaching management.

German university management has few structure level, fine personnel, high efficiency, clear power and responsibility, which achieves better self-management. Compared with Germany university, our universities still lack of selfmanagement ability, and have many problems, such as lacking of the legislation safeguard of self-management, the governing body being too complex, unreasonable structure of management level, unclear responsibility and power of management agency. Therefore we must expand university's power of self-running and self-management, streamline institutions, clearly define responsibilities and powers, providing good environment for university self-management, and enhancing the university's adaptability and flexibility.

\section{E. Stakeholder participation}

German universities establish a stakeholder's governance system which involves government, school and social institutions. Stakeholders participate in university governance, which is beneficial to the counterbalance of power and fairness of decision-making. Senior managers such as government and headmaster, and staff, students, graduate alumni, local community and the public are all closely linked with the existence and development of universities.

University is a stakeholder organization, and its all decisions need to take the profits of all stakeholders into consideration. Learning from experiences about German university governance, China establishes multilateral governance structure in the reform of higher education. It introduces competition mechanisms and form common governance pattern of stakeholders participating in university governance, which allow the decision-making of university to strike a balance between many stakeholders.

\section{DRAW LESSONS FROM GERMAN UNIVERSITY'S GOVERNANCE PATTERN}

Germany is a country that liberalism and individualism prevail. German public is more accustomed to relying on their own strength to solve problems, rather than relying on government mainly. Therefore, various civil powers tend to have an impact on the development direction of university organization according to their own will and interests. Under the circumstances, German government can attach more importance to embodying its own interest demand when funding colleges, and let a portion of the public's requirement for university be achieved through their own donation. But in China, the party and government "represent the fundamental interests of the broadest masses of the people", which makes the fund of government embody richer and more diverse social requests in the process of supporting universities. The Chinese government's spending responsibility on universities is greater than German government's apparently. Therefore, government will occupy an important position in the future pattern of Chinese university governance structure.

China and Germany have a huge difference in institution and culture. Different nature of states determines that we can't 
directly copy German's experience on some issues. As we know, it is an inevitable choice of universities in socialist country to adhere to our party's leading role in university, especially in the ideological domain, and the leading position of Marxist in college culture, the first principle of our country's four cardinal principles is "adhering to the leading of party". Therefore, the "principal accountability under the leadership of the party committee" must be insisted and developed anyway. The reform of university's internal governance structure can fully learn from and absorb useful experience about German university's governance structure within the framework of" principal accountability under the leadership of the party committee". The high academic freedom and professor managing of German university governance structure are the most important content that our country should refer to.

\section{CONCLUSION}

In short, the university governance structural system construction in China has a very long way to go, and universities bear the important historical mission. To establish the Chinese characteristic modern university governance structural system, we must fully follow the rules of Chinese higher education and administer the school by laws. First, adhere to the core role of Party committee in the university governance; Second, construct the responsibility and power relation system between school Party committee and different administrative levels; Third, construct and improve statutes of university and academic committee, establish system adapting to the structure of modern university governance. Clarify the responsibility and power relationship about administrative body, and the academic committee and other academic organization's boundary of burden and power, operation procedure and methods, bestow on the professor-centered academic committee practical decision-making system in academic affair.

\section{ACKNOWLEDGMENT}

The authors would like to thank financial support by the project of the Reform project of Heilongjiang Province: (JG2014011046), Jiamusi University teaching research project (2016JW1009), Jiamusi University degree and postgraduate education teaching reform project (JGXM-JDY-2016011) and Heilongjiang institute of higher education project(16G206).

\section{REFERENCES}

[1] Xu Liqin, Du Wei,Feng Jun, Ye Han.Cultivation of Application-oriented Undergraduate Talents Based on the Experience of German Universities of Applied Sciences [J].Research in Higher Education of Engineering,2008,02:96-99.

[2] ZHONG Xiao- fei. German Experience and University of Application Nature[J]. Journal of Ningbo University of Technology,2008,03:1-4.

[3] OU Yang-yi, YANG De-hua. On the Revelation of the Successful Experience of Cooperative Education in America, England and German to the Construction of our Applied Universities[J]. Future and Development,,2009,07:73-76.

[4] HAN Dao-you. Improve Independent Entrepreneurship Education of Applied University Student by Referencing to Experience of German Universities[J]. Journal of Hefei University(Natural Sciences),2011,02:62-64+81.

[5] Wang Yingchun Tianjin University of Technology Tianjin Liu Wenjuan Tianjin University of Technology Tianjin. Effect of the structure of university's R\&D funds on the outcome of invention patents in JiangSu province[A]. Wuhan Sports University, China,China Institute of Sport Science,Beijing,China.Proceedings of 2010 International Conference on Computer Science and Sports Engineering (CSSE 2010)[C].Wuhan Sports University, China,China Institute of Sport Science,Beijing,China:,2010:3.

[6] Xueqin Zi. A Tentative Study on Dimension Structure of University Brand values[A]. (AAMSA)(Asian Association of Management Science \& Applications(AAMSA)). [C]. (AAMSA)(Asian Association of Management Science \& Applications(AAMSA)):,2013:1.

[7] Ming Jiang. Formation and Characteristics Analysis on Dissipative Structure of University Continuing Education Management Ability System[A]. Information Engineering Research Institute.Proceedings of 2013 International Conference on Creative Education (ICCE 2013)Volume 3[C].Information Engineering Research Institute:,2013:5.

[8] Wang Yingchun,Liu Wenjuan. Effect of the Structure of university's R\&D Funds on the Outcome of Invention Patents in JiangSu Province[A]. Intelligent Information Technology Application Association.Proceedings of the 2011 International Conference on Future Computer Science and Education(ICFCSE 2011)[C].Intelligent Information Technology Application Association:,2011:3.

[9] Preben Terndrup Pedersen. Marine Structures: Future Trends and the Role of Universities[J]. Engineering,2015,01:131-138.

[10] Shujuan Zhang,Ling Xu. Case Studies of University Funds Source Structure Impact on University Rankings in U.S.[A]. Advanced Science and Industry Research Center.Proceedings of 2014 International Conference on Education Reform and Modern Management(ERMM 2014 V75)[C].Advanced Science and Industry Research Center:, 2014:5. 